there was more or less flexibility of the elbow; in 13, anchylosis. Several of these men were useful as carpenters, as they could use their shoulders in a hinge-joint fashion, such as planing wood, cutting with a hatchet or chisel, etc., which they manifestly could not do if they had lost the arm by previous surgery of last century. Resection of the elbow was every where amongst the French less dangerous than amputation of the humerus, from the prevalence of this disease, osteo-myelitis.

It is very interesting to find Dr. Menzies, and in London such an eminent surgeon as Mr. Skey, in a clinical address this month on amputations, now adopting the opinions of the surgeons of 1848 , that I then published. Such is the congruousness of truth and fact, in spite of the anomalies of statistics. Dr. Menzies, like many surgeons after great battles, gives an opinion that one will find in all our medical libraries amongst old books, that more in the Crimea might have been left to conservative surgery and the vis medicatrix, or, as M. Velpeau expressed it in 1848 , "Plus je viellis dans le pratique moirzs je suis partisan de l'amputation."

\section{ON THE USE OF CUBEBS IN THE TREATMENT OF GONORRHEA.}

By H. Burfond Norjran, Esq., F.R.C.S., Consulting Surgeon to the St. Pancras Provident Dispensary, and to the St. Marylebone Charity Schools.

[Read bejore the North Lonilon Melical Socicty, April 26th, 1856.]

[Concluded from page 500.]

So varied in degree of severity are attacks of gonorrhœa in different persons, that the question was at one time much debated among the authorities on renereal diseases, whether they were not occasioned by specifically different poisons. The true cause of these differences was very clearly assigned to the habit of body by Whately, Howard, Roberton, and others, who wrote on the subject with much experience in the beginning of the present century, and has been very clearly observable to me in my own practice-so clearly, that I know nothing analogous equal to it, but that which is often to be observed in cases of ophthalmia, in which the pain, redness, and sensibility of the affected organ all bear a clear relation to the weakness and irritability of the whole frame, and especially, perhaps, to that of the organs of digestion.

Bearing in mind these differences of habit which prevail in different individuals, we must not be surprised to find that the cubebs not only fails, in some instances, to produce its best effects, but sometimes also causes inconveniences. What these are, and how to obviate them, I shall now endeavour to point out.

They are, nausea, headache, rertigo, hot flushings of the cheeks and hands, heartburn, acid eructations, diarrhœea, occasionally constipation, and, it is said, swelled testicle. The latter, I do not think, is justly attributable to the remedy; for certain it is, that from the time we possess any accounts of the gonorrhcea it has been one of the accidents most commonly occurring in the course of the complaint. It would little profit us now to go over the various modes of accounting for its occurrence, according to the notion regarding the discase and the proper method of treating it, prevalent at different periods. But it cannot fail to instruct our judgments in reference to our present remedies, to bear in memory the fact that this complication has been at all times common, and that cvery remedy in turn proposed for the cure of gonorrhoea has had to bear the blame of its production. Of one thing I feel very strongly convinced respecting it, viz., that if we can succeed in checking the discharge from the urethra quickly, without the application of any active and violent topical remedy to the inflamed canal itself, we place the patient in the most farourable condition to escape the accident. There are many reasons why this should be: 1st. In the beginning of the attack the inflammation is confined to the forepart of the urethra. 2nd. The coustitution is then little affected. 3rd. For a few days we often can control the whole habits of the patient, and adopt all those precautions which may check the tendency to a further inflammatory attack on the subsidence of the first; amongst which, rest in the recumbent position is the most important ; frequent steaming of the perinæum the second; saline and other diaphoretic drinks, with Dorer's powder, a third. Violent purging I think has no good effect. It irritates and teases the patient, and renders the urine acrid; but a daily evacuation, procured by such a medicine as the compound jalap powder, the tartrate of potass, or seidlitz powder, taken fasting in the morning, is, in almost every casc, advantageous.

The other evils attributed to the use of cubebs are partly due to the patient, partly to the remedy, and partly to a neglect of due precaution on the part of the prescriber. They are all connected so far with the patient that they arise from his stornach not readily digesting the medicine: and similar effects would be produced by any similar irritating and indigestible matter. Many persons cannot take spiced or seasoned food without feeling more or less of similar conscquences; and of course when there is added to the stimulating influence of the essential oil contained in the powders of the cubebs, the presence of a large quantity of hard woody fibre, its effects will sometimes be very disagreeable. Can anything be done to mitigate or to prevent them? I think, much. In the first place, we should give the powder as fine as we can possibly get it: secondly, be most particular that it is fresh, so that we derive the fullest effects from the smallest effective dose: thirdly, we may combine with it some sedative, saline, or other medicine, as the carbonate or tartrate of soda, the carbonate, tartrate, or nitrate of potass and hydrocyanic acid. Frequent draughts of cold water, or the sucking of lumns of ice, tend to lessen much the irritability of such weak stomachs, and to enable them to bear with tolerable patience this medicine, and other things which would otherwise bc intolerable. In all cases, a free state of the bowels, maintained by daily giving a quick but not irritating purgative on the patient's first waking in the morning, tends much to counteract the irritating effects of the medicine, and to lessen its purgative quality, which, when the drug is not adulterated with other purgative matter, seems rather to depend upon its mechanically irritating the intestines, like bran, fruit seeds, and other similar articles, than upon any other cause. Where the powder produces the opposite state of constipation, which is not frequent, it seems again to act mechanically in patients of a different stomach from the preceding class. In these it fails to irritate at all, and must be dislodged by aperients. I think there are very few if any cases in which the offence of the cubebs is more than I have thus endeavoured to explain, and in which it may not be made tolerable, and at the samc time the most efficient remedy which we possess. Until latcly but little advantage has been derived from any preparation of this drug. The alcoholic tincture and the essential oil have been long in use; but neither of them with much benefit-for this reason, that each wants the chief active principle of the drug, viz., an oleo-resin closely resembling in its properties the balsam of copaiba. The essential oil has, I believe, some influence on the urethral discharges; but the resinous oil is the remedy par excellence. In the preparation which I now introduce to you, both of these are combined; and it is obtained by acting on cubebs separately by ether and alcohol, evaporating each tincture at a low temperature, and mixing their residue. I am inclined to expect from this preparation much advantage and freedom from the objection attaching to the powder. Ten drops of it equal at least a drachm of good cubebs powder. At present it is chiefly used in the form of capsules. From experience, I can say but little about it, as I have only lately been acquainted with this preparation, and the powder has afforded me very satisfactory results. All that any medicine can do in the treatment of gonorrbœa is so often undone by the inability or unwillingness of the patient to con- 
form eren for short period to a regular course of life, to take rest, and avoid exposure to injurious influences, that there will always be long and tedious cases to regor these wo must not blame the medicine, nor gepreciate our art. Purgatives, abstinence, rest, and such lite means, are of little avail alone. Injections, from all that I have observed, and carefully weighing what I have read in thoir favour, are of exceedingly uncertain worth, and, I believe, are best calculated for the last stage of the complaint, over which the cubebs seem to have but little control. Copaiba is liable to many of the objections. which attach to cubebs, and its horrible taste makes it to many people a remedy as disgusting as the disease, while the footid exhalations from the luniss and skin of one taking it are often disagreeably perceptible to the noses of his neighbours. I think its positive influcnce over the discharge, too, is less than that of the cubebs in the early stage; but it has seemed to me, like injections, very capable of carrying on and completing a cure commenced with cubebs, if it does not proceed satisfactorily. United in a paste, these two medicines were a very favourite remedy with the late Mr. Liston, and are still often prescribed. There is this disadvantage attending the combination, that it is using up both your principal resources at once, when it might be more prudent to keep one in reserve, to follow up the effects obtained by the other, besides its being a somewhat loathsome form. I therefore seldom prescribe it. Blisters in the perinæum are of value in chronic cases, where the disease is reduced to a gleet, but objectionable on the score of their great inconvenience. In this stage of the disease, where as yet there is no stricture, cold bathing, a coutse of tonic remedies, and change of air, are of the greatest service; but specifics are of little worth. In some of these instances, where the patient and doctor are both wearied out, and a cure seems as distant as ever, and nothing does good, it is not a bad plan to abstain entirely from all treatment for a time, and for the patient to take plenty of exercise, and live freely. This will cause the more active symptoms of the disease to reappear, in which case the cubebs, given again in as full doses as the patient can bear, sometimes brings about the wished for result-a speedy and complete cure. So also if a fresh infection is received by a patient still troubled with a wearisome gleet, the second attack will often yield readily to the remedy which the former had resisted.

It will be perceired from what I have now said that I do not attribute the present neglect of the cubebs to its having been introduced with too high encomium at first; but perhaps sufficient experience of its use had not at the time of the first reports in its favour been enjoyed to estimate quite correctly the ill effects which it might occasion, and to ascertain the best means of preventing or combating them. Hence dissatisfaction and disappointment may have often followed their exhibition. Adulterations of the drug, too, have been practised, not only with black pepper, as stated by Mr. Crauford, but also, as I learn from other sources, with pimento and linseed meal. Dr. Paris, too, tells us in his Pharmacologia, published in 1821, that even at that time the pepper was adulterated with the berries of the rhammus catharticus. Dr. Hassall has kindly examined a number of specimens for me lately, procured from various chemists and apothecaries, but fails to detect any adulterations in these. Where no adulteration exists, the medicine is often bad from long and careless keeping. Sometimes it is not nearly so finely powdered as it might and should be; and all these things tend to lessen its value and the dependence to be placed on its efficacy. But a much more frequent source of disappointment is the exhibition of the medicine in too small doses, and, in particular cases, without due precautions and aids. Some of these I have already hinted at; I cannot pretend to treat of them fully. The failures which thus arise are attributed to the medicine unfairly; they should be attributed to another cause, if, as I have said, these precautions can be used with effect. But more powerful than all the other causes of the decadence of this remedy, as of many others, from the high position which it once enjojed, and, as I have said before, I think it deserved, is to be sought and found in the fickleness of fashion and the love of novelty, which are allowed to hare sway over our minds, and which cause us to neglect very much that careful study of means already proved to be good, by which we may acquire most skill to wield them in the relief of suffering, and in the battle with disease and death.

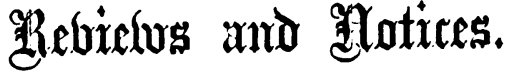

Varicose VeIns : their Nature, Consequences, and Treatment. By Henry T. ChapMan, F.R.C.S. pp. 99. 8vo. London: Churchill. 1856.

Thrs monograph places before the profession in a more formal manner a system of treatment by means of wet strapping and bandaging, described some few years since in the Medical Times and Gazette. The author says :-

"Placing the patient on a low seat, and elevating the foot until the veins empty themselves by the gravitation of the blood towards the trunk, I apply wet straps of linen or calico, blood towards the trunk, I apply w Mr. Scott applied adhesive precisely in the sam the straps a calico roller is carefully put plaster."...." Over the straps a calico roller is carefully put on, the greatestere entire limb. Through its texture the course of the varicose veins should be moistened several times daily with cold water, diluted Goulard lotion or solution of alun,, sulphate of zinc or chloride of lime." (p. 76.)

In certain cases, recourse is had to "compresses of lint, or spongio-piline, in combination with the bandage, large or chers and each of the sacculated portions of the vein separately, and thick enough to close their channels."

Mr. Cra PMaN discusses the methods of compression as practised by Mr. Worsnald, Mr. Colles, and Mr. Nunn; and also those operations for the obliteration of dilated veins, which have over and over again been followed by such lamentable results, even when performed under apparently the most favourable circumstances. Operations he condemns:-firstly, as ineffectual; and secondly, as unjustifiable.

The practical part of Mr. Chapman's essay is prefaced by "an abstract of the most authentic details we possess on the subject", which the author says he has taken pains to verify.

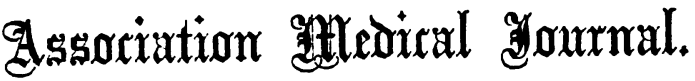

SATURDAY, JULY 5TH, 1856.

\section{LONDON VEGETATION AND LONDON SMOKE.}

THE roses in the Middle Temple Garden, after having ceased to bloom for many years, have again made their appearance. This announcement might seem an insignificant one to the medical reader, but it is a text on which a profitable discourse may be preached by all sanitarians throughout the country. The gardener of the honourable Society tells the world, in a letter to the Times, that this great event has been brought about by the Smoke Prevention Act-that we literally have in this city roses once more by Act of Parliament. Those who remember the river Thames five years ago, and see it now, can indeed understand the thankfulness with which the son of earth rejoices over the 